While it is certainly more difficult to acquire the skill and technique of pelvic examination in the left lateral position, once acquired, it is not only as effective a means of pelvic examination but the pouch of Douglas is more easily assessed, and, as Marion Sims discovered, the anterior wall of the vagina is much better visualized. Howkins rightly draws attention to this in Operative Gynaecology. ${ }^{1}$ There can be no doubt whatsoever that this method of gynaecological examination is much less embarrassing for the patient. With its special advantages, it would be a pity if it were discarded simply to mimic our transatlantic colleagues.-I am, etc.,

Windsor.

Stanley Simmons.

REFERENCB

Sharw's Textbook of Operative Gymaecology, 3rd
edition, ed. J. Howkins, 1968, p. 36. London.

\section{Abortion and Huntington's Chorea}

SrR,-Dr. M. J. Pleydell (10 February, p. 376) and Dr. J. E. Oliver (2 March, p. 576) have already suggested that the statement in the report of the B.M.A. Committe on Therapeutic Abortion (20 January, p. 171) that pregnancy is rare in women suffering from Huntington's chorea should be accepted with some reservation. I have been able to calculate figures which may be of interest from a series which I am collecting within the area of the Western Regional Hospital Board, the full results of which I hope to publish shortly.

Of 179 women, 5 conceived a total of 15 children after onset of the disease, 3 others were first noticed to be affected during pregnancy, and in 5 onset may also have preceded the birth of their last child. Two women who developed the full clinical picture after their families had been completed had had a psychiatric illness in their late teens. Thus between 5 and 15 of the 179 women $(2.7-8.3 \%)$ bore children after onset of the disease.

As Dr. Oliver points out, the wife of a choreic male may bear children after the onset of the disease in her husband, and of 157 male choreics 8 had a total of 16 children born to them after onset of the disease, 5 had a total of 10 children born after the probable onset, and 2 each had a child born about the time of onset, so that between 8 and $15(5.1-9.6 \%)$ had children born after onset. In a condition such as Huntington's chorea, where the symptoms may not be recognized for years after their first appearance, it is difficult to be precise in retrospect about the date of onset, but it seems possible that the proportion of patients who are affected before their children are conceived may be higher than that quoted above, since 4 of the 44 women personally examined conceived children after the onset, two of them, indeed, being affected before marriage. Bearing in mind the average age of onset of around 40 years, a relatively large proportion of patients will develop the disease at an age when they might well have further children. In this series $9.9 \%$ (both sexes combined) developed the disease between 20 and 29 years, $9.4 \%$ between 30 and 34 years, and $18.4 \%$ between 35 and 39 years.

In conclusion, Dr. Oliver's suggestion of a nation-wide medical linkage system, together with registration of affected families, would go some way towards making more positive advice, and incidentally support, available to these unfortunate families. - I am, etc.,

$$
\begin{aligned}
& \text { Leverndale Hospital, JEAN M. W. BoLt. } \\
& \text { Glasgow S.W.3. }
\end{aligned}
$$

\section{Moment of Death}

SIR,-The television meeting between Professor C. Barnard and some British medical experts was highly interesting but unfortunately did not deal with the blunt question which lay people have frequently asked meand probably most of my colleagues-since the first heart transplant operation. Does the heart donor die naturally? Professor Barnard's epoch-making operation arouses concern as well as admiration. Indeed, the moral question raised far transcends the wonder of his achievement, and one can only wait with anxiety an answer to the question posed.

The term "cabbage" has been much in use lately-not necessarily by Professor Barnard-and embodies a challenge to fundamental ethics. It harbours a logic which knows no bounds and which can bode ill not only for healthy defectives but for other defenceless forms of human life possibly deemed useless or undesirable by society or, more accurately, by someone with the power so to deem. The issues are completely different from those involved in euthanasia where the termination of a life is based solidly upon the wish of its possessor. They are also different from those confronting nuclear physicists, whose achievements can subsequently be used for good or bad and do not include ipso facto the taking of human life.

Perhaps all the fears are groundless and will be completely allayed by an authoritative statement. Without reassurances, devoid of ambiguity, one cannot but echo the general fear.-I am, etc.,

Crosby, Liverpool.

Norman S. BarNetT.

\section{Post-vagotomy Diarrhoea}

SIR,-Mr. M. J. N. Frohn and others (24 February, p. 481) are surely right in asserting that vagotomy is fast spreading as part of the standard treatment of duodenal ulceration, and that the routine operation in most centres is a total abdominal vagotomy. I suggest that some surgeons feel that the bilateral selective operation may lead to incomplete vagotomy as far as the stomach is concerned. Indeed, in Fig. 1 accompanying their article it would seem that fibres from the hepatic plexus may reach the pyloric antrum after anterior selective vagotomy. How then can it be ensured that the cephalic phase of gastric acid secretion is entirely abolished ?

Mr. Frohn and colleagues state that $\mathrm{Kraft}^{2}$ and Smith and Farris ${ }^{2}$ halved their incidence of post-vagotomy diarrhoea after abandoning the total in favour of bilateral selective vagotomy. Still, after the latter procedure the incidence was respectively $19 \%$ and $12 \%$ relatively high, I submit. Harkins and his colleagues' figures, cited by Mr. Frohn and his colleagues, for the selective operation plus antrectomy show a reduced incidence of post- operative diarrhoea from $68 \%$ to $29 \%$. Their figures are of crucial import, as in the operation of vagotomy and antrectomy gastric acid secretion is reduced by $95 \%$. Hence the suspicion that "persistent episodic diarrhoea" is-may I quote Professor Stammers and Mr. J. A. Williams ?'-" more suggestive of increased susceptibility to intestinal infection due to loss of the gastric acid trap" than other factors. One notes in this connexion the abrupt improvement in the diarrhoea obtainable by use of an oral antibiotic.

I wonder, therefore, which factor is more important in post-vagotomy diarrhoeabacterial content of jejunum or denervation of extragastric organs such as liver, biliary apparatus, or pancreas. I would applaud the efforts of Mr. Frohn and his team tc find out for us if the selective operation, properly performed, will solve the problem Indeed, their series of 321 cases of vagotomy and pyloroplasty for duodenal ulcer is : remarkably large one considering the number of cases of chronic ulcer which, owing to deformity, scarring, and sclerosis, would be considered unsuitable for pyloroplasty.I am, etc.,
Mercy Hospital,
Cork, Ireland.
P. B. KIEIY

REPERENCES

Kraft, R. O., Fry, W. J., and Ransom, H. K Arch. Surg., 1962, 85, 687. M., Arch. Surg Stammers, F. A. R., and Willizms, J. A.. Parria Gastrectomy, 1963, p. 272. London.

\section{Hypertension in the Tropics}

SrR,-We wish to congratulate Professor K. L. Stuart for his article (13 January, $p$ 103) on the above subject.

This article is quite timely, because during a recent visit to Britain one of us found it hard to convince colleagues that hypertension and its complications-cardiovascular and cerebrovascular - are a problem to physician who work in the tropics. Professor Stuar has brought out some of these difficulties very clearly.

We also wish to support the view that one of the most important functions of a treatment programme for hypertension in the tropics is educational.

We are to undertake a survey of hypertension in the hospital population in Freetown very soon, and we hope to publish the results in a few years. - We are, etc.,

\section{E. M. F. LURE} W. A. RENNER.

Hill Station Hospital,

Freetown, Sierra Leone.

\section{Malaria Originating in Britain}

SIR,-Recent correspondence has stressed the need to check the geographical personal history of patients suffering from an undiagnosed and possibly puzzling remittent febrile condition, and the cases quoted have shown that the malaria now diagnosed originated previously in an endemic malarial area. But this is by no means the only need. In certain areas of England, and with appropriate weather conditions and temperatures $\left(60^{\circ} \mathrm{F}\right.$. $\left(16^{\circ} \mathrm{C}\right.$.) for $3-6$ weeks), malaria may be acquired from chronic malarial 